\title{
Hypogastric Nerve Plexus
}

National Cancer Institute

\section{Source}

National Cancer Institute. Hypogastric Nerve Plexus. NCI Thesaurus. Code C52831.

Either of two (inferior or superior) hypogastric nerve plexi in the lower abdomen. 